\title{
Desempenho de frangos de corte e digestibilidade de rações com sorgo ou milheto e complexo enzimático
}

\author{
Paulo Ricardo de Sá da Costa Leite(1), Nadja Susana Mogyca Leandro(2), José Henrique Stringhini(2), \\ Marcos Barcellos Café(2), Natali Almeida Gomes ${ }^{(2)}$ e Roberto de Moraes Jardim Filho(3)
}

\begin{abstract}
(1)Instituto Federal Goiano, Campus Ceres, Rodovia GO 154, Km 03, CEP 76300-000 Ceres, GO. E-mail: prleite@yahoo.com.br (2)Universidade Federal de Goiás, Escola de Veterinária, Departamento de Produção Animal, Campus Samambaia, CEP 74001-970 Goiânia, GO. E-mail: mogyca@vet.ufg.br, jhstring@hotmail.com, mcafe@vet.ufg.br, natalivetufg@yahoo.com.br ${ }^{(3)}$ Abatedouro São Salvador, Rodovia GO 156, Km 0, s/no, Zona Rural, CEP 76630-000 Itaberaí, GO. E-mail: robertomjf@superfrango.com.br
\end{abstract}

\begin{abstract}
Resumo - O objetivo deste trabalho foi avaliar a digestibilidade de rações formuladas com sorgo (Sorghum bicolor), ou milheto (Pennisetum glaucum) e adição de um complexo enzimático comercial composto de amilase, carboidrases, proteases e fitase, e o desempenho de frangos de corte. Para avaliação de desempenho, foram alojados 1.800 pintos de corte machos em delineamento em blocos ao acaso, em arranjo fatorial $2 \times 2$, com quatro tratamentos (rações com sorgo ou milheto com ou sem adição de complexo enzimático) e cinco repetições com 60 aves por unidade experimental. Nos ensaios de metabolismo realizados dos 10 aos 14 e dos 24 aos 28 dias, foram distribuídos 420 pintos machos em delineamento inteiramente casualizado, em esquema fatorial 2x2 (rações com milheto ou sorgo com ou sem adição de complexo enzimático). Os dados foram submetidos à análise de variância e as médias comparadas com o teste F para contrastes ortogonais. Nas rações elaboradas com sorgo, a adição do complexo enzimático proporcionou melhores coeficientes de digestibilidade da gordura e do nitrogênio. A adição de complexo enzimático em rações formuladas com sorgo melhora a conversão alimentar somente na fase inicial de criação dos frangos, enquanto a adição de complexo enzimático não melhora o desempenho de frango nas rações elaboradas com milheto.
\end{abstract}

Termos para indexação: Pennisetum glaucum, Sorghum bicolor, conversão alimentar, nutrição animal.

\section{Broiler performance and digestibility of sorghum or millet diets with enzymatic complexes}

\begin{abstract}
The objective of this work was to evaluate the digestibility of sorghum (Sorghum bicolor) or millet (Pennisetum glaucum) diets with the addition of a commercial enzymatic complex formed by amylase, carbohydrases, proteases and phytase, and broiler performance. For performance evaluation, 1,800 male broilers were distributed in a randomized complete block design in a $2 \times 2$ factorial arrangement, with four treatments (sorghum or millet diet with or without addition of enzymatic complex), and five replicates of 60 birds per experimental unit. In the metabolism assays carried out at 10 to 14 and 24 to 28 days, 420 male broilers were distributed in a completely randomized block design in a $2 \times 2$ factorial arrangement (millet or sorghum diet with or without addition of enzymatic complex). Data were submitted to variance analysis and averages were compared by the $\mathrm{F}$ test for orthogonal contrasts. In diets formulated with sorghum, the addition of the enzymatic complex provided better coefficients of digestibility of fat and nitrogen. The addition of the enzymatic complex in diets formulated with sorghum improves feed conversion ratio only in the initial phase of raising broilers, while the addition of the enzymatic complex does not improve broiler performance in diets formulated with pearl millet.
\end{abstract}

Index terms: Pennisetum glaucum, Sorghum bicolor, feed conversion ratio, animal nutrition.

\section{Introdução}

O milho e o farelo de soja são os ingredientes vegetais mais utilizados nas rações de frangos de corte em razão de seu valor nutritivo e também de sua disponibilidade no mercado brasileiro. Contudo, durante o ano, há oscilação de preços dos principais ingredientes utilizados nas rações avícolas, principalmente no preço do milho que aumenta na entressafra. Portanto, alimentos energéticos com menor custo que podem substituir o milho em rações de frangos são opções para nutricionistas em determinadas épocas do ano.

Entre os alimentos energéticos disponíveis em algumas regiões, sobretudo no Centro-Oeste brasileiro, estão o sorgo e o milheto. $\mathrm{O}$ valor nutricional do sorgo na alimentação das aves é conhecido e considerado

Pesq. agropec. bras., Brasília, v.46, n.3, p.280-286, mar. 2011 
alto, de 85 a 95\%, em comparação ao milho, o que torna viável a substituição total do milho. O grão de milheto apresenta teor de proteína bruta superior e conteúdo de lisina semelhante ao do milho, embora esses ingredientes tenham menor valor de energia metabolizável em comparação ao milho (Rostagno et al., 2005).

Em geral, os ingredientes vegetais utilizados nas rações de frangos apresentam fatores antinutricionais, como polissacarídeos não amídicos e fitato, que dificultam a absorção de nutrientes e o desempenho de frangos (Bedford, 2000). Malathi \& Devegowda (2001) encontraram 9 e $29 \%$ de fatores antinutricionais na forma de polissacarídeos não amídicos no milho e no sorgo e no farelo de soja, respectivamente. O farelo de soja pode apresentar ainda inibidores de tripsina, lectinas, rafinose e estaquiose, que dificultam a absorção de nutrientes (Graham et al., 2002; Rodrigues et al., 2003).

Ao serem adicionadas nas rações, algumas enzimas exógenas são capazes de aumentar a digestibilidade dos nutrientes de rações à base de milho e farelo de soja, o que pode estar associado à degradação dos fatores antinutricionais presentes nestes alimentos. Assim, a adição de complexo enzimático em rações elaboradas com esses ingredientes reduz a variabilidade nutricional, o que resulta em maior disponibilidade de nutrientes da dieta e melhor desempenho de frangos (Odetallah et al., 2005; Onderci et al., 2006).

Strada et al. (2005) verificaram que a adição de complexo enzimático em rações à base de milho e farelo de soja para frangos de corte de 22 a 42 dias de idade melhorou a eficiência de utilização da energia metabolizável e dos aminoácidos, como metionina, metionina + cistina e lisina. Oliveira et al. (2007) também constataram melhor digestibilidade ileal de matéria seca, proteína bruta, cálcio e fósforo, ao adicionar complexo enzimático (celulase, protease, amilase e fitase) em rações de frango formuladas com milho e farelo de soja. Olukosi et al. (2007) obtiveram melhor peso dos frangos aos 21 dias de idade quando as rações foram suplementadas com enzimas exógenas (amilase, protease, xilanase e fitase).

Em experimento com pintos de corte até 21 dias de idade com rações elaboradas com sorgo ou milheto, Strada et al. (2005) não verificaram efeito da suplementação de protease, amilase e xilanase sobre o desempenho dos frangos. Portanto, o tipo de ingrediente utilizado na dieta, entre outros fatores, como as enzimas que compõem o produto comercial, pode influenciar os resultados.

O objetivo deste trabalho foi avaliar a digestibilidade de rações formuladas com sorgo ou milheto e adição de um complexo enzimático comercial composto de amilase, carboidrases, proteases e fitase, e o desempenho de frangos de corte.

\section{Material e Métodos}

Foram realizados dois experimentos, um de desempenho e outro de metabolismo. O experimento de desempenho foi conduzido no aviário experimental da empresa Super Frango, Itaberaí, GO. Foram utilizados 1.800 pintos de corte machos da linhagem Cobb 500, alojados em dois galpões $24 \times 6,65 \mathrm{~m}$ (divididos em 16 boxes de 2,10x2,50 m). Em cada boxe, foram colocados um bebedouro pendular e dois comedouros tubulares, com densidade de alojamento de 11,4 aves por metro quadrado.

Utilizou-se delineamento experimental de blocos ao acaso em arranjo fatorial, tendo sido o fator bloco o galpão. Foram estudados dois tipos de ingredientes energéticos nas rações (sorgo e milheto) com ou sem complexo enzimático, o que totalizou quatro tratamentos: ração formulada com sorgo sem complexo enzimático, ração formulada com sorgo com complexo enzimático, ração formulada com milheto sem complexo enzimático e ração formulada com milheto com complexo enzimático, com cinco repetições e 60 aves por unidade experimental.

As rações eram fareladas e foram formuladas de acordo com a matriz nutricional da empresa Super Frango que atende os níveis nutricionais de cada fase de criação. A adição do complexo enzimático Allzyme SSF, foi realizada na ração basal na forma "on top", sem considerar as vantagens da enzima na matriz nutricional para a formulação das dietas. O complexo enzimático era composto pelas enzimas amilase, pectinase, $\beta$-glucanase, pentosanase, celulase, protease e fitase, e a adição do produto na ração seguiu a recomendação do fabricante: 200 g por tonelada de ração. As rações experimentais foram testadas em três fases de criação - pré-inicial, inicial e de crescimento -, sendo todas as rações isonutrientes e isoenergéticas. A ração final - a mesma para todos os tratamentos foi elaborada com o ingrediente energético milho, sem complexo enzimático. 
Foram avaliados peso médio, ganho de peso, consumo de ração e conversão alimentar dos frangos nas diferentes fases de criação (1 a 7 dias, 1 a 21 dias, 1 a 35 dias) e no período total (1 a 42 dias). A conversão alimentar foi calculada pela relação entre o ganho de peso e o consumo de ração, tendo sido utilizado como critério de correção o peso das aves mortas nas diferentes fases e no período total.

Para o ensaio de metabolismo, foram alojados 420 pintos de corte machos de um dia de idade $(43,2 \pm 0,54 \mathrm{~g})$ da linhagem Cobb $500 \mathrm{em}$ baterias metálicas, instaladas em galpão de alvenaria no setor de avicultura da Universidade Federal de Goiás. Os tratamentos consistiram de dois tipos de ingredientes energéticos na ração (milheto ou sorgo) associados ou não à adição de Allzyme SSF, o mesmo complexo enzimático utilizado no ensaio de desempenho. As rações eram fareladas, e as rações das fases inicial e de crescimento foram utilizadas para o ensaio de digestibilidade (Tabela 1). A ração e a água foram fornecidas à vontade, tendo sido calculado o consumo de ração. O programa de luz utilizado foi de 23 horas de luz, semelhante ao ensaio de desempenho.
O delineamento utilizado foi inteiramente casualizado, em esquema fatorial, com sete repetições de 15 aves cada. O ensaio metabólico foi conduzido com base no método de coleta total de excretas, realizado em dois períodos: do décimo ao décimo quarto dia e do vigésimo quarto ao vigésimo oitavo dia de vida. As excretas foram coletadas duas vezes ao dia e congeladas, e, posteriormente, foram realizadas as análises bromatológicas, segundo metodologia de Silva \& Queiroz (2002). Foram calculados os coeficientes de digestibilidade de massa de matéria seca (CDMS), gordura (CDG), energia metabolizável (CDEM), nitrogênio total (CDN) e balanço de nitrogênio $(\mathrm{BN})$.

Os resultados de desempenho e do ensaio metabólico foram submetidos à análise de variância com auxílio do programa estatístico SAS Institute (2000), e as médias foram comparadas pelo teste $\mathrm{F}$ para contrastes ortogonais, a $5 \%$ de probabilidade.

\section{Resultados e Discussão}

No período de 10 a 14 dias de idade, o CDG melhorou com a adição do complexo enzimático nas

Tabela 1. Composição percentual e calculada das rações experimentais de frangos de corte das fases pré-inicial (1 a 7 dias), inicial ( 8 a 21 dias) e de crescimento (22 a 35 dias).

\begin{tabular}{|c|c|c|c|c|c|c|}
\hline \multirow[t]{2}{*}{ Ingrediente } & \multicolumn{2}{|c|}{ Pré-inicial } & \multicolumn{2}{|c|}{ Inicial } & \multicolumn{2}{|c|}{ Crescimento } \\
\hline & Sorgo & Milheto & Sorgo & Milheto & Sorgo & Milheto \\
\hline Sorgo & 58,49 & - & 62,10 & - & 64,65 & - \\
\hline Milheto & - & 65,35 & - & 69,04 & - & 72,19 \\
\hline Farelo de soja & 31,52 & 25,31 & 28,34 & 21,96 & 25,71 & 18,86 \\
\hline Farelo de carne e ossos & 5,65 & 5,83 & 5,36 & 5,56 & 4,19 & 4,39 \\
\hline Gordura de aves & 2,83 & 1,93 & 3,11 & 2,17 & 3,96 & 2,97 \\
\hline Sal comum & 0,35 & 0,35 & 0,33 & 0,34 & 0,33 & 0,34 \\
\hline Fosfato bicálcico & - & - & - & - & 0,40 & 0,41 \\
\hline DL-Metionina & 0,30 & 0,27 & 0,20 & 0,27 & 0,15 & 0,12 \\
\hline L-Lisina & 0,36 & 0,46 & 0,06 & 0,16 & 0,11 & 0,22 \\
\hline Suplemento mineral e vitamínico ${ }^{(1)}$ & 0,50 & 0,50 & 0,50 & 0,50 & 0,50 & 0,50 \\
\hline Total & 100,0 & 100,0 & 100,0 & 100,0 & 100,0 & 100,0 \\
\hline \multicolumn{7}{|l|}{ Composição calculada } \\
\hline Proteína bruta $(\%)$ & 21,85 & 21,85 & 20,65 & 20,65 & 19,10 & 19,10 \\
\hline EM (kcal kg-1) & 2.925 & 2.925 & 2.980 & 2.980 & 3.050 & 3.050 \\
\hline Lisina total $(\%)$ & 1,43 & 1,43 & 1,11 & 1,11 & 1,05 & 1,05 \\
\hline Metionina total (\%) & 0,66 & 0,67 & 0,51 & 0,55 & 0,44 & 0,45 \\
\hline Metionina + Cistina total $(\%)$ & 1,02 & 1,02 & 0,84 & 0,87 & 0,76 & 0,76 \\
\hline Cálcio (\%) & 0,94 & 0,94 & 0,89 & 0,89 & 0,82 & 0,82 \\
\hline Fósforo disponível (\%) & 0,46 & 0,46 & 0,44 & 0,44 & 0,44 & 0,44 \\
\hline
\end{tabular}

(1)Suplemento vitamínico e mineral por kg de produto: 10.000 UI de vitamina A; 2.000 UI de vitamina D3; $12.500 \mathrm{mg}$ de vitamina E; $2.500 \mathrm{mg}$ de vitamina $\mathrm{K} 3 ; 2.400 \mathrm{mg}$ de vitamina B1; $6.000 \mathrm{mg}$ de vitamina B2; $3.200 \mathrm{mg}$ de vitamina B6; $12.000 \mathrm{mcg}$ de vitamina B12; $1.000 \mathrm{mg}$ de ácido fólico; $12.500 \mathrm{mg}$ de pantotenato de cálcio; $30.000 \mathrm{mg}$ de niacina; $15 \mathrm{~g}$ de antioxidante; $200 \mathrm{mg}$ de selênio; $7,5 \mathrm{~g}$ de bacitracina de zinco; $1.000 \mathrm{~g}$ de veículo q.s.p.; $12.000 \mathrm{mg}$ de cobre; $40.000 \mathrm{mg}$ de ferro; $1.000 \mathrm{mg}$ de iodo; $6,4 \mathrm{~g}$ de anticoccidiano; $65.000 \mathrm{mg}$ de manganês; $50.000 \mathrm{mg}$ de zinco. 
rações formuladas com sorgo, enquanto a adição do complexo enzimático diminuiu o balanço de nitrogênio nas rações formuladas com milheto (Tabela 2). Assim, o complexo enzimático teve influência positiva nas dietas elaboradas com o sorgo, mas foram observadas desvantagens para o milheto.

Aos 28 dias de idade, o complexo enzimático melhorou os coeficientes CDMS, CDG, CDN, CDEM e o BN em rações formuladas com sorgo, e somente CDG em rações com milheto. Segundo Simon et al. (2002), a suplementação de enzimas que degradam polissacarídeos não amídicos em rações de frangos de corte diminui a viscosidade, tendo como resposta a melhora na digestibilidade dos nutrientes, especialmente da gordura.

Os melhores coeficientes de digestibilidade observados neste trabalho para as rações formuladas com sorgo confirmam a ação do complexo enzimático utilizado na degradação dos nutrientes das rações, com posterior absorção e aproveitamento pelas aves. A adição de carboidrases exógenas em dietas, mesmo que contenham ingredientes com menor conteúdo de polissacarídeos não amídicos, como no caso do sorgo, melhora a digestibilidade dos nutrientes. Rodrigues et al. (2003) verificaram que a adição de complexo enzimático em rações à base de milho melhorou a digestibilidade da massa de matéria seca e da proteína bruta. Meng et al. (2004) observaram que as enzimas melhoraram a digestibilidade da gordura, em rações elaboradas com trigo.

Houve efeito do tipo de ingrediente energético da ração sobre a digestibilidade dos nutrientes somente no período de 24 a 28 dias de idade, e as rações formuladas com sorgo proporcionaram maior coeficiente de digestibilidade de CDMS, CDG e CDEM, em comparação às rações elaboradas com milheto.

No ensaio de desempenho, na fase pré-inicial (Tabela 3), não houve diferença para os dados de desempenho. As rações formuladas com sorgo ou milheto proporcionaram peso final e ganho de peso semelhantes aos dos sete dias de idade. O efeito da adição enzimática não foi observado nas rações formuladas com sorgo ou milheto. De acordo com Olukosi et al. (2007), pintos de corte apresentam imaturidade do trato gastrintestinal com menor produção de enzimas endógenas e pior digestibilidade dos nutrientes da ração. Estudos com a adição de complexo enzimático, em rações elaboradas com milho e farelo de soja na fase pré-inicial, confirmam a importância das enzimas na degradação da parede celular dos vegetais, com melhor absorção dos nutrientes e desempenho de frangos de corte (Gracia et al., 2003; Costa et al., 2007).

No período de 1 a 21 dias de idade (Tabela 4), foi observada diferença para conversão alimentar entre frangos alimentados com rações elaboradas com milheto ou sorgo. As rações com sorgo proporcionaram melhor conversão alimentar em comparação às com milheto, independentemente da adição ou não do complexo enzimático. A adição do complexo enzimático nas rações elaboradas com sorgo melhorou a conversão alimentar de frangos na fase inicial de criação, em comparação aos resultados das rações elaboradas com sorgo sem complexo enzimático. Nas rações elaboradas

Tabela 2. Coeficientes de digestibilidade da massa de matéria seca (CDMS), gordura (CDG), nitrogênio total (CDN) e da energia metabolizável (CDEM) e balanço de nitrogênio (BN) de frangos alimentados com rações com milheto ou sorgo, com adição de complexo enzimático (CE), no período de 10 a 14 dias e de 24 a 28 dias de idade.

\begin{tabular}{|c|c|c|c|c|c|c|c|c|c|c|}
\hline \multirow[t]{3}{*}{ Tratamento } & \multicolumn{5}{|c|}{$10-14$ dias } & \multicolumn{5}{|c|}{ 24-28 dias } \\
\hline & CDMS & CDG & $\mathrm{CDN}$ & CDEM & \multirow{2}{*}{$\begin{array}{l}\mathrm{BN} \\
(\mathrm{g})\end{array}$} & CDMS & CDG & $\mathrm{CDN}$ & CDEM & \multirow{2}{*}{$\begin{array}{l}\mathrm{BN} \\
(\mathrm{g})\end{array}$} \\
\hline & \multicolumn{4}{|c|}{ 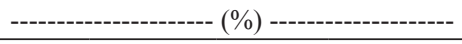 } & & \multicolumn{4}{|c|}{ 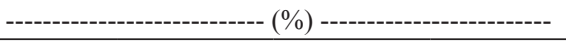 } & \\
\hline Sorgo & 43,70 & 73,24 & 41,93 & 55,04 & 22,48 & 66,79 & 73,24 & 39,53 & 66,79 & 24,28 \\
\hline Sorgo $+\mathrm{CE}$ & 43,92 & 82,63 & 47,42 & 52,01 & 14,23 & 72,81 & 82,63 & 50,41 & 72,81 & 44,56 \\
\hline Milheto & 47,65 & 62,42 & 32,13 & 50,06 & 27,89 & 61,15 & 62,42 & 30,51 & 61,16 & 30,15 \\
\hline Milheto + CE & 42,65 & 74,80 & 35,24 & 46,95 & 16,92 & 64,18 & 74,80 & 28,60 & 64,18 & 28,60 \\
\hline $\mathrm{CV}(\%)$ & 5,86 & 8,95 & 7,52 & 5,01 & 7,87 & 6,45 & 8,95 & 6,45 & 16,31 & 35,45 \\
\hline \multicolumn{11}{|c|}{ Teste F contraste ortogonal } \\
\hline Sorgo x milheto & ns & ns & ns & ns & ns & $*$ & $*$ & $\mathrm{~ns}$ & $*$ & ns \\
\hline Sorgo x Sorgo CE & ns & $*$ & ns & ns & ns & $*$ & $*$ & $*$ & $*$ & $*$ \\
\hline Milheto x Milheto CE & ns & ns & ns & ns & $*$ & ns & $*$ & ns & ns & ns \\
\hline
\end{tabular}


com milheto, não houve efeito da adição do complexo enzimático sobre o desempenho dos frangos. Esses resultados concordam parcialmente com os obtidos por Morais et al. (2002), Strada et al. (2005) e Santos et al. (2006), ao observar que a adição de complexo enzimático em rações formuladas com sorgo e milheto não melhoraram o desempenho de frangos na fase inicial de criação.

Os melhores resultados com a adição do complexo enzimático (amilase, pectinase, $\beta$-glucanase, pentosanase, celulase, protease e fitase) observados em rações elaboradas com sorgo estão de acordo com as pesquisas realizadas com a adição de complexo enzimático em rações de frangos à base de milho e farelo de soja, na fase inicial de criação (Brito et al., 2006; Olukosi et al., 2007; Ao et al., 2009).
No período de 1 a 35 dias de idade (Tabela 4), houve efeito do tipo de ingrediente energético utilizado na ração no desempenho de frangos. A ração com sorgo, em comparação à com milheto, proporcionou melhor conversão alimentar. Nas rações elaboradas com sorgo ou milheto, não houve efeito da adição do complexo enzimático sobre o desempenho dos frangos. Resultados semelhantes foram relatados por Rodrigues et al. (2003), Pinheiro et al. (2004) e Yu \& Chung (2004), ao adicionar enzimas em rações à base de milho e farelo de soja para frangos de corte.

Quando se considera o período de até 42 dias de idade para verificar o efeito dos tratamentos (35 dias de idade) sobre o período total de criação, pode-se observar que a ração elaborada com sorgo proporcionou melhor conversão alimentar aos frangos, em comparação às

Tabela 3. Desempenho de frangos de corte alimentados com rações contendo sorgo ou milheto, com adição de complexo enzimático (CE), no período de 1 a 7 dias de idade.

\begin{tabular}{|c|c|c|c|c|c|}
\hline Tratamento & Peso inicial & Peso final & Ganho de peso & Consumo de ração & $\begin{array}{c}\text { Conversão alimentar } \\
\qquad\left(\mathrm{g} \mathrm{g}^{-1}\right)\end{array}$ \\
\hline Sorgo & 43,27 & 180,58 & 137,31 & 191,73 & 1,06 \\
\hline Sorgo $+\mathrm{CE}$ & 43,61 & 183,27 & 139,67 & 174,48 & 0,96 \\
\hline Milheto & 43,23 & 179,88 & 136,65 & 203,46 & 1,14 \\
\hline Milheto $+\mathrm{CE}$ & 42,81 & 187,01 & 144,24 & 190,76 & 1,02 \\
\hline $\mathrm{CV}(\%)$ & 2,21 & 3,71 & 4,71 & 9,57 & 11,13 \\
\hline \multicolumn{6}{|l|}{ Teste F contraste ortogonal } \\
\hline Milheto x sorgo & $\mathrm{ns}$ & ns & ns & $\mathrm{ns}$ & ns \\
\hline Sorgo $\mathrm{CE} \times$ milheto $\mathrm{CE}$ & ns & ns & ns & ns & ns \\
\hline Sorgo $\mathrm{x}$ sorgo CE & ns & ns & ns & ns & ns \\
\hline Milheto $\mathrm{x}$ milheto $\mathrm{CE}$ & ns & ns & ns & $\mathrm{ns}$ & ns \\
\hline
\end{tabular}

nsNão significativo.

Tabela 4. Desempenho de frangos de corte alimentados com rações contendo sorgo ou milheto, com adição de complexo enzimático (CE), no período de 1 a 21 e 1 a 35 dias de idade.

\begin{tabular}{|c|c|c|c|c|c|c|c|c|}
\hline \multirow[t]{4}{*}{ Tratamento } & \multicolumn{4}{|c|}{$1-21$ dias } & \multicolumn{4}{|c|}{$1-35$ dias } \\
\hline & Peso & Ganho & Consumo & \multirow{3}{*}{$\begin{array}{c}\text { Conversão } \\
\text { alimentar } \\
\left(\mathrm{kg} \mathrm{kg}^{-1}\right)\end{array}$} & Peso & Ganho & Consumo & \multirow{3}{*}{$\begin{array}{c}\text { Conversão } \\
\text { alimentar } \\
\left(\mathrm{kg} \mathrm{kg}^{-1}\right) \\
\end{array}$} \\
\hline & final & de peso & de ração & & final & de peso & de ração & \\
\hline & ------------ & $(\mathrm{kg})--$ & ------------- & & -------- & $-(\mathrm{kg})-$ & ------- & \\
\hline Sorgo & 847,84 & 804,57 & 1,25 & 1,57 & 2,15 & 2,11 & 3,40 & 1,62 \\
\hline Sorgo $+\mathrm{CE}$ & 875,72 & 832,12 & 1,23 & 1,48 & 2,12 & 2,08 & 3,45 & 1,67 \\
\hline Milheto & 849,30 & 806,07 & 1,32 & 1,65 & 2,11 & 2,06 & 3,63 & 1,77 \\
\hline Milheto + CE & 873,20 & 830,43 & 1,31 & 1,59 & 2,13 & 2,09 & 3,68 & 1,77 \\
\hline $\mathrm{CV}(\%)$ & 2,98 & 3,15 & 4,93 & 4,06 & 2,99 & 3,06 & 5,92 & 4,72 \\
\hline \multicolumn{9}{|l|}{ Teste F contraste ortogonal } \\
\hline Milheto x sorgo & ns & ns & ns & $*$ & ns & ns & $\mathrm{ns}$ & $*$ \\
\hline Sorgo CE x milheto CE & ns & ns & $*$ & $*$ & ns & ns & $\mathrm{ns}$ & ns \\
\hline Sorgo $x$ sorgo $\mathrm{CE}$ & ns & ns & ns & $*$ & ns & ns & ns & ns \\
\hline Milheto x milheto CE & ns & ns & $\mathrm{ns}$ & ns & ns & ns & ns & ns \\
\hline
\end{tabular}

ns Não significativo. *Significativo a $5 \%$ de probabilidade. 
rações à base de milheto, independentemente da adição ou não de complexo enzimático (Tabela 5). Não houve efeito positivo do complexo enzimático em rações formuladas com milheto em todas as fases estudadas e, com sorgo, somente até aos 21 dias de idade.

Como as enzimas são específicas para o substrato e, portanto, para o tipo de ingrediente, em função da variação da composição química de cada alimento, o complexo enzimático utilizado nas rações provavelmente não foi capaz de melhorar a degradação, digestão e absorção dos nutrientes, principalmente nas rações elaboradas com milheto. O complexo enzimático comercial utilizado neste trabalho pode ser um produto desenvolvido, sobretudo, para rações elaboradas com milho. Conforme Tejedor et al. (2001), para a adição de enzimas em rações, é importante conhecer a composição dos ingredientes utilizados na ração e a especificidade da enzima com relação ao substrato.

Os resultados deste trabalho quanto aos efeitos positivos da utilização de complexos enzimáticos em rações para frangos foram contrários aos relatos de Graham et al. (2002) e Rodrigues et al. (2003), ao estudar enzimas em rações à base de milho e farelo de soja. Segundo esses autores, a adição de complexo enzimático em dietas com farelo de soja pode proporcionar melhores resultados de desempenho de frangos em virtude da degradação de fatores antinutricionais presentes no farelo de soja. A enzima galactosidase é a responsável pela degradação da rafinose e da estaquiose presentes no farelo de soja, que correspondem a aproximadamente $6 \%$ da massa de matéria seca do farelo de soja e prejudicam

Tabela 5. Desempenho de frangos de corte alimentados com rações contendo sorgo ou milheto, com adição de complexo enzimático (CE), até os 35 dias de idade, no período total de criação (1 a 42 dias de idade).

\begin{tabular}{lcccc}
\hline Tratamento & $\begin{array}{c}\text { Peso } \\
\text { final }\end{array}$ & $\begin{array}{c}\text { Ganho } \\
\text { de peso }\end{array}$ & $\begin{array}{r}\text { Consumo } \\
\text { de ração }\end{array}$ & $\begin{array}{c}\text { Conversão } \\
\text { alimentar } \\
\left(\mathrm{kg} \mathrm{kg}^{-1}\right)\end{array}$ \\
\hline Sorgo & 2,50 & 2,46 & 4,32 & 1,79 \\
Sorgo + CE & 2,54 & 2,49 & 4,49 & 1,83 \\
Milheto & 2,43 & 2,39 & 4,65 & 1,97 \\
Milheto + CE & 2,50 & 2,46 & 4,72 & 1,93 \\
\hline CV $(\%)$ & 5,15 & 5,24 & 5,74 & 3,87 \\
\hline Teste F contraste ortogonal & & & & \\
Milheto x sorgo & $\mathrm{ns}$ & $\mathrm{ns}$ & $\mathrm{ns}$ & $*$ \\
Sorgo CE x milheto CE & $\mathrm{ns}$ & $\mathrm{ns}$ & $\mathrm{ns}$ & $\mathrm{ns}$ \\
Sorgo x sorgo CE & $\mathrm{ns}$ & $\mathrm{ns}$ & $\mathrm{ns}$ & $\mathrm{ns}$ \\
Milheto x milheto CE & $\mathrm{ns}$ & $\mathrm{ns}$ & $\mathrm{ns}$ & $\mathrm{ns}$ \\
\hline
\end{tabular}

${ }^{{ }_{n}}$ Não significativo. *Significativo a $5 \%$ de probabilidade. a absorção de nutrientes, pois esses oligossacarídeos não são digeridos no intestino delgado das aves, em razão da falta da enzima $\alpha$-1,6-galactosidase (Graham et al., 2002).

Já que o complexo utilizado neste trabalho não possuía galactosidase em sua composição, é possível que as diferenças nos resultados entre as pesquisas também estejam associadas à composição enzimática. Para rações elaboradas com milheto e farelo de soja, são necessários estudos mais complexos, como o desenvolvimento de enzimas que utilizem estes ingredientes como substrato.

\section{Conclusões}

1. A digestibilidade dos nutrientes da ração melhora com a adição do complexo enzimático em dietas elaboradas com sorgo.

2. A adição do complexo enzimático que contém amilase, pectinase, $\beta$-glucanase, pentosanase, celulase, protease e fitase, em rações formuladas com sorgo, melhora a conversão alimentar somente na fase inicial de criação dos frangos.

3. A adição do complexo enzimático, nas rações elaboradas com milheto, não proporciona ganho no desempenho de frango.

\section{Referências}

AO, T.; CANTOR, A.H.; PESCATORE, A.J.; FORD, M.J.; PIERCE, J.L.; DAWSON, K.A. Effect of enzyme supplementation and acidification of diets on nutrient digestibility and growth performance of broiler chicks. Poultry Science, v.88, p.111-117, 2009.

BEDFORD, M.R. Exogenous enzymes in monogastric nutrition their current value and future benefits. Animal Feed Science and Technology, v.86, p.1-13, 2000.

BRITO, C.O.; ALBINO, L.F.T.; ROSTAGNO, H.S.; GOMES, P.C.; DIONÍZIO, M.A.; CARVALHO, D.C.O. Adição de complexo multienzimático em dietas à base de soja extrusada e desempenho de pintos de corte. Revista Brasileira de Zootecnia, v.35, p.457-461, 2006.

COSTA, F.G.P.; BRANDÃO, P.A.; BRANDÃO, J.S.; SILVA, J.H.V. da. Efeito da enzima fitase nas rações de frango de corte, durante as fases pré-inicial e inicial. Ciências Agrotécnicas, v.31, p.865-870, 2007.

GRACIA, M.I.; ARANÍBAR, M.J.; LÁZARO, R.; MEDEL, P.; MATEOS, G.G. Alpha-amylase supplementation of broiler diets based on corn. Poultry Science, v.82, p.436-442, 2003.

GRAHAM, K.K.; KERLEY, M.S.; FIRMAN, J.D.; ALLEE, G.L. The effect of enzyme treatment of soybean meal on oligosaccharide disappearance and chick growth performance. Poultry Science, v.81, p.1014-1019, 2002. 
MALATHI, V.; DEVEGOWDA, G. In vitro evaluation of nonstarch polysaccharide digestibility of feed ingredients by enzymes. Poultry Science, v.80, p.302-305, 2001.

MENG, X.; SLOMINSKI, B.A.; GUENTER, W. The effect of fat type, carbohydrase, and lipase addition on growth performance and nutrient utilization of young broilers fed wheat-based diets. Poultry Science, v.83, p.1718-1727, 2004.

MORAIS, E.; FRANCO, S.G.; FEDALTO, L.M. Efeitos da substituição do milho pelo sorgo, com adição de enzimas digestivas, sobre o ganho médio de peso de frangos de corte. Archives of Veterinary Science, v.7, p.109-114, 2002.

ODETALlAH, N.H.; WANG, J.J.; GARLICH J.D.; SHIH, J.C.H. Versazyme supplementation of broiler diets improves market growth performance. Poultry Science, v.84 p.858-864, 2005.

OLIVEIRA, M.C. de; CANCHERINI, L.C.; GRAVENA, R.A.; RIZZO, P.V.; MORAES, V.M. de. Utilização de nutrientes de dietas contendo mananoligossacarídeo e/ou complexo enzimático para frangos de corte. Revista Brasileira de Zootecnia, v.36, p.825-831, 2007.

OLUKOSI, O.A.; COWIESON, A.J.; ADEOLA, O.; AYDIN, $\mathrm{S}$. Age-related influence of a cocktail of xylanase, amylase, and protease or phytase individually or in combination in broilers. Poultry Science, v.86, p.77-86, 2007.

ONDERCI, M.; SAHIN, N.; SAHIN, K.; CIKIM, G.; AYDÍN, A.; OZERCAN, I.; AYDÍN, S. Efficacy of supplementation of alpha-amylase-producing bacterial culture on the performance, nutrient use, and gut morphology of broiler chickens fed a corn-based diet. Poultry Science, v.85, p.505-510, 2006.

PINHEIRO, D.F.; CRUZ, V.C.; SARTORI, J.R.; VICENTINO PAULINO, M.L.M. Effect of early feed restriction and enzyme supplementation on digestive enzyme activities in broilers. Poultry Science, v.83, p.1544-1550, 2004.
RODRIGUES, P.B.; ROSTAGNO, H.S.;ALBINO, L.F.T.; GOMES, P.C.; BARBOZA, W.A.; TOLEDO, R.S. Desempenho de frangos de corte, digestibilidade de nutrientes e valores energéticos de rações formuladas com vários milhos suplementadas com enzimas. Revista Brasileira de Zootecnia, v.32, p.171-182, 2003.

ROSTAGNO, H.S.; ALBINO, L.F.T.; DONZELE, J.L.; GOMES, P.C.; OLIVEIRA, R.F. de; LOPES, D.C.; FERREIRA, A.S.; BARRETO, S.L. de T. Tabelas brasileiras para aves e suínos: composição de alimentos e exigências nutricionais. Viçosa: UFV, 2005. 187 p.

SANTOS, M. do S.V. dos; ESPÍNDOLA, G.B.; FUENTES, M. de F.F.; FREITAS, E.R.; CARVALHO, L.E. de. Utilização de complexo enzimático em dietas à base de sorgo-soja para frangos de corte. Revista Brasileira de Zootecnia, v.35, p.811-817, 2006.

SAS INSTITUTE. SAS/STAT: user's guide. Versão 6.11. $4^{\text {th }} \mathrm{ed}$. Cary: SAS Institute, 2000. v.2, 842p.

SILVA, D.J.; QUEIROZ, A.C. de. Análise de alimentos: métodos químicos e biológicos. 3.ed. Viçosa: UFV, 2002. 235p.

SIMON, O.; HÜBENER, K.; HIRSCH, K.; BECKMANN, L.; VAHJEN, W. Effect of xylanases on the intestinal flora. Lohmann Information, n.27, p.1-5, 2002.

STRADA, E.S. de O.; ABREU, R.D.; OLIVEIRA, G.J.C. de; COSTA, M. do C.M.M. da; CARVALHO, G.J.L. de; FRANCA, A.S.; CLARTON, L.; AZEVEDO, J.L.M. de. Uso de enzimas na alimentação de frangos de corte. Revista Brasileira de Zootecnia, v.34, p.2369-2375, 2005.

TEJEDOR, A.A.; ALBINO, L.F.T.; ROSTAGNO, H.S.; LIMA, C.A.R. de; VIEITES, F.M. Efeito da adição de enzimas em dietas de frangos de corte à base de milho e farelo de soja sobre a digestibilidade ileal de nutrientes. Revista Brasileira de Zootecnia, v.30, p.809-816, 2001.

YU, B.; CHUNG, T.K. Effects of multiple-enzyme mixtures on growth performance of broilers fed corn-soybean meal diets. The Journal of Applied Poultry Research, v.13, p.178-182, 2004.

Recebido em 13 de julho de 2010 e aprovado em 17 de janeiro de 2011

Pesq. agropec. bras., Brasília, v.46, n.3, p.280-286, mar. 2011 